\title{
Emotional Responses Toward Humans in Monkeys with Selective Frontal Lesions'
}

\author{
CHARLES M. BUTTER, MORTIMER MISHKIN² AND ALLAN F. MIRSKY ${ }^{3}$ \\ University of Michigan, Ann Arbor
}

(Received 18 May 1967)

\begin{abstract}
BUTter, C. M., M. MISHKIn AND A. F. MIRsky. Emotional responses toward humans in monkeys with selective frontal lesions. Physiol. Behav. 3 (2) 213-215, 1968.-Monkeys with lateral or orbital frontal lesions, operated controls with inferotemporal lesions and unoperated controls were tested for aggressive and aversive responses toward humans as judged by three observers. Contrary to expectations based upon previous findings, the frontal monkeys failed to show decreased avoidance of humans, and the orbital frontal monkeys showed increased avoidance compared with the other groups.
\end{abstract}

Lateral frontal cerebral cortex Orbital frontal cerebral cortex Lesions Avoidance of humans

SEvERAL studies have suggested that emotional reactivity in monkeys is altered by damage to the frontal lobes. For example, following both lateral and ventral prefrontal ablations, monkeys show abnormally rapid extinction of preoperatively learned avoidance responses [8], and following prefrontal lobotomy they show decreased avoidance of shock [10] and decreased avoidance of other, more dominant monkeys in a social colony [1]. Such findings appear to indicate that frontal lesions lead to a generalized reduction in fear. In an attempt to gather further information on this point we employed a simple behavioral test similar to one described by Mason, Green \& Posepanko [6]. The test is based on the observation that staring at a monkey's eyes frequently evokes from the animal a strong aversive or aggressive reaction. We applied this test to monkeys with lateral or orbital prefrontal lesions as well as to operated and unoperated controls.

METHOD

Subjects

The subjects were 45 rhesus monkeys (Macaca mulatta) of both sexes, ranging in weight from 3.5 to $7 \mathrm{~kg}$. They were housed individually in double-tier cages. Four to eight months prior to the present series of observations, the lateral prefrontal cortex had been removed bilaterally in 14 monkeys, the orbital frontal cortex in 8 , and the inferotemporal area in $11 ; 12$ were unoperated controls. Descriptions of the surgical and histological techniques, and reconstructions of representative lesions from each group, are contained in other experimental reports dealing with the same animals $[4,5]$. The distribution of males and females, and of upper and lower cage locations, was approximately the same for the four groups.

\section{Procedure}

All subjects were observed nine times: three times, on separate days, by each of three observers. Observations were made at times of the day during which there was little or no commotion in the animal quarters. The observer, wearing a white laboratory coat, approached the monkey's cage and recorded its name and number inscribed on the cage front. The observation period then lasted for $20 \mathrm{sec}$, during which the observer stood immobile in front of the subject's cage, stared directly (and impassively) at the subject's eyes whenever they were turned toward the observer, and noted the subject's behavior. Immediately after the observation period, the observer recorded (in code) the occurrence, frequency and sequence of the behaviors listed in Table 1 .

TABLE 1

Behaviors Observed in Testing

\begin{tabular}{|c|c|}
\hline Aggression & Avoidance \\
\hline $\begin{array}{l}\text { Attack-lunging at observer and } \\
\text { reaching for observer with hand } \\
\text { Vocalization } \dagger\end{array}$ & $\begin{array}{l}\text { Running from side to side in } \\
\text { back of cage } \\
\text { Climbing up cage away from } \\
\text { observer }\end{array}$ \\
\hline $\begin{array}{l}\text { Head thrust } \dagger \\
\text { Mouth threat } \dagger \\
\text { Frown } \dagger \\
\text { Ears back } \dagger\end{array}$ & $\begin{array}{l}\text { Body aversion } \\
\text { Turning away from observer } \\
\text { Head and/or eye aversion } \\
\text { Lip smacking* } \\
\text { Grimacing* }\end{array}$ \\
\hline
\end{tabular}

†Behaviors frequently accompanying aggressive movements toward observer.

*Behaviors frequently accompanying aversion to observer.

${ }^{1}$ This study was performed during the tenure of a USPHS Postdoctoral Fellowship by the senior author at the Section on Neuropsychology, National Institute of Mental Health.

'Address: National Institute of Mental Health, Bethesda, Maryland.

Address: Boston University School of Medicine, Boston Massachusetts. 
While some of the behaviors listed are not themselves obviously aggressive or aversive in character, they are so classified, since each of them is frequently accompanied by either aggressive movements (attack) or aversive movements (such as turning away from the observer).

\section{RESULTS}

For the initial analyses, an animal's score consisted of the total number of its aggressive or aversive responses, including repeated occurrences of the same response, recorded during one observation period. Figure 1 presents the mean frequency of these responses for each of the four groups as judged by each observer. The scores for each observer are averaged over his three sets of observations since there were no consistent effects of observation order.
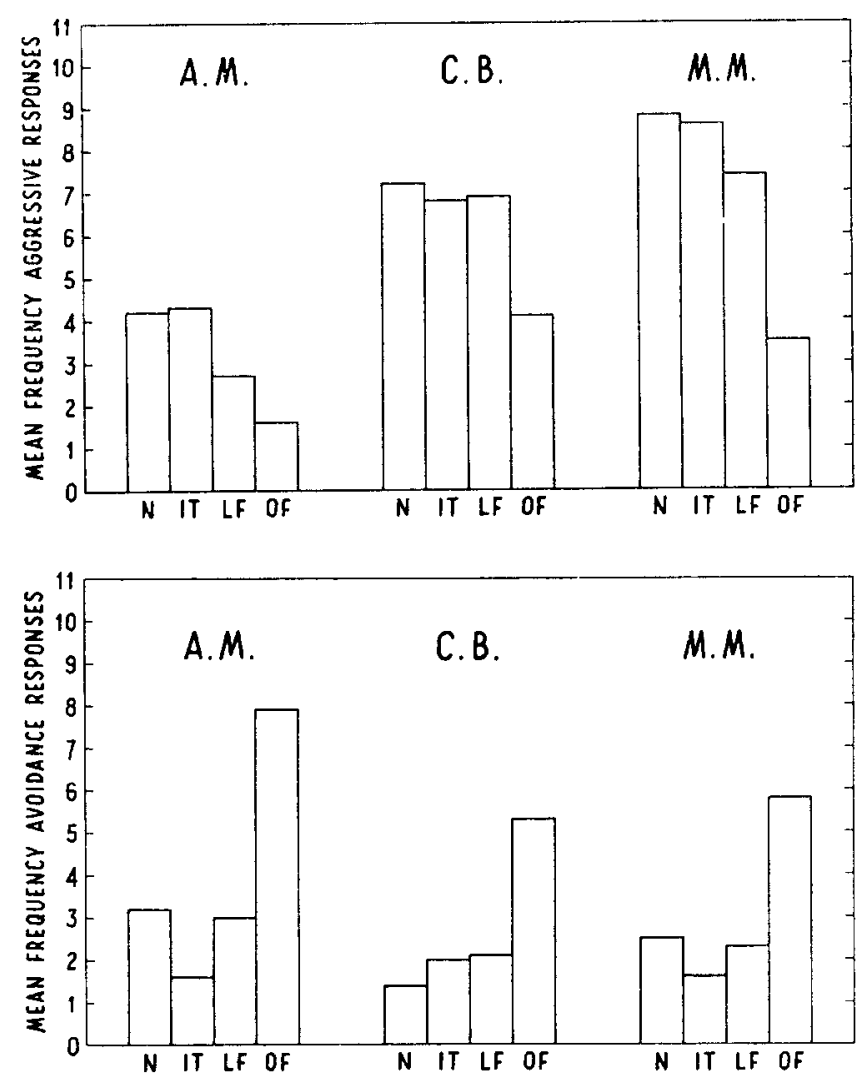

FIG. 1. Mean frequencies of aggressive (upper half) and aversive (lower half) responses of the four groups as judged by each observer.

Inter-observer reliability, evaluated by Pearson $r$ 's, was fairly high for the judgments of aggression frequency in the 45 monkeys $(0.77,0.79,0.82)$, but was somewhat lower for the judgments of avoidance frequency $(0.67,0.71,0.75)$. Because of these instances of low reliability, and because analyses of variance revealed significant differences among the ratings of the three observers $(p<0.01$ for aggression; $p<0.05$ for avoidance), group differences were analyzed separately for each observer.

As indicated in Fig. 1, each of the three observers judged the animals in the orbital frontal group to be both the least frequently aggressive and the most frequently avoiding of all the groups. With regard to the aggression ratings, analyses of variance performed separately for each observer failed to disclose any significant group effects. For the avoidance scores, however, analyses of variance revealed significant group effects for all observers ( $p<0.01$ for A.M.; $p<0.05$ for both C.B. and M.M.). Furthermore, $t$-tests comparing mean frequencies of avoidance in the normal and orbital frontal groups yielded differences significant beyond the 0.02 level for one observer (M.M.), beyond the 0.01 level for another (A.M.) and beyond the 0.005 level for the third (C.B.). Finally, a comparison of the mean frequencies of avoidance in the orbital frontal group and in the two other operated groups combined yielded differences significant beyond the 0.01 level for all observers.

The avoidance data were analyzed further to determine which specific behaviors were primarily responsible for the orbital group's high scores on the overall measures. For this analysis, repetitions of a particular response within an observation period were excluded to avoid the bias that might result from comparing brief responses tending to have a high repetition rate, such as "lip-smacking", with protracted and less readily repeated behaviors such as "climbing". In the judgments of one observer (A.M.), the orbital group scored abnormally high on "head and eye aversion" $(p<0.01)$. Although no other specific behaviors differentiated the groups reliably, it is clear from inspection of Fig. 2 that the orbital animals consistently received the highest ratings on all of them with the exception of "running from side to side in the back of the cage". The same group differences were found when repetitions of a given response were included in the analyses.

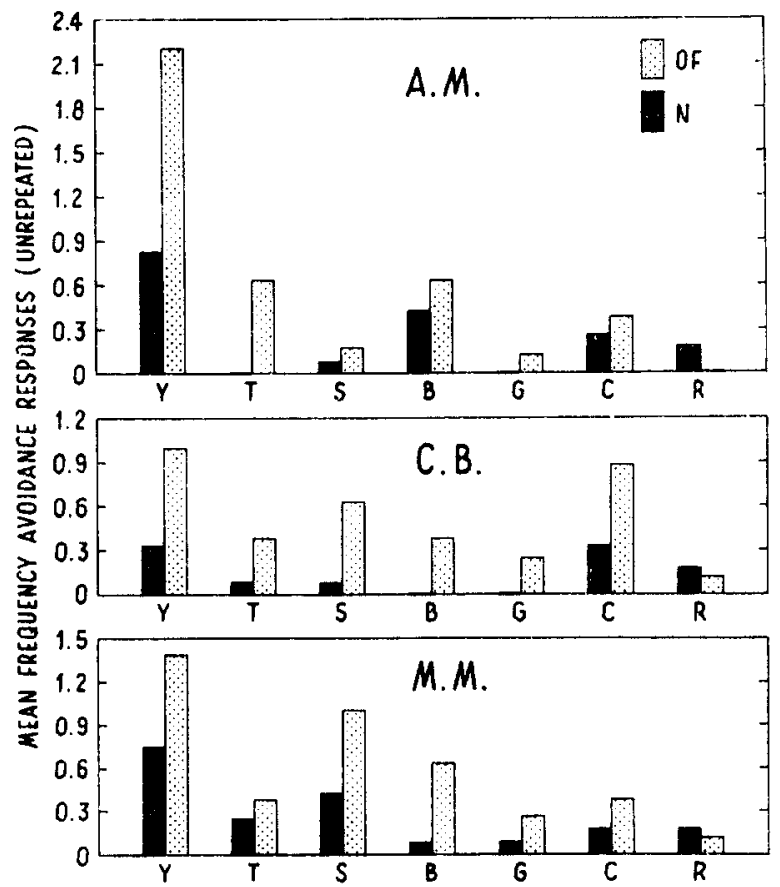

FIG. 2. Mean frequencies of avoidance responses of the orbital frontal and normal groups as judged by each observer, excluding repeated responses within each observation period. $Y=$ head and/or eye aversion; $T=$ turning away from observer; $S=$ lip smacking; $\mathrm{B}=$ body aversion; $\mathbf{G}=$ grimace; $\mathrm{C}=$ climbing up cage away from observer; $R=$ r.- running from side to side in back of cage. 


\section{DISCUSSION}

Because the procedure employed in this experiment confounds the observer with the stimulus, three different "stimulus-observers" were used. As it turned out, the pattern of results for the three observers was highly consistent, however. Each observer elicited and scored avoidance reactions more frequently in the orbital frontal group than in any of the others. This consistency in the data cannot readily be attributed either to the observer's familiarity with the animal's lesion status (one observer had no such knowledge and the two others had incomplete knowledge) or to observer bias (the selectivity and direction of the group differences were both unanticipated). As to the significant differences which were found between the results for the three observers, it might be pertinent that all observers were not equally familiar to the monkeys and they may therefore have provoked somewhat different emotional reactions. Such a possibility is favored by the finding that the avoidance ratings of the three observers tended to be inversely proportional to their aggression ratings.

Although the findings thus appear to be reliable, there are several reasons for urging caution in interpreting them. First, the observations were limited ones; a proper evaluation of emotional alterations must eventually take into account many other aspects of individual as well as group cagebehavior. Second, any conclusion that frontal lesions lead to heightened fear of human observers would be at variance with the suggestion derived from instrumental and social situations that frontal damage in monkeys reduces fear. It is conceivable of course that frontal damage may alter emotionality in opposite directions depending on the testing situation. Rosvold, Mirsky \& Pribram [9] found just such an effect following amygdala damage in monkeys: decreased avoidance of human observers coupled with increased submissiveness in a social group. Other resolutions of the paradox may also be possible. As suggested recently by Brutkowski [2], postoperative conditioned avoidance performance could be disrupted by incompatible responses accompanying heightened fear, as well as by a loss of fear. As to decreased avoidance in a social colony, it is difficult to determine whether an operated animal's fear has lessened or whether its drive for some goal such as food, a mate or a preferred location has increased. Finally, it should be noted that the different emotional changes inferrable from this and other studies $[1,8,10]$ have been produced by different types of frontal lesions. Until some of these behavioral and anatomical variables have been sorted out, and the apparent discrepancies explained, it would be hazardous to place undue emphasis on the present limited, but suggestive, findings

\section{REFERENCES}

1. Brody, E. B. and H. E. Rosvold. Influence of prefrontal lobotomy on social interaction in a monkey group. Psychosom. Med. 14: 406-415, 1952.

2. Brutkowski, S. Functions of prefrontal cortex in animals. Physiol. Rev. 45: 721-746, 1965.

3. Butter, C. M. Habituation of responses to novel stimuli in monkeys with selective frontal lesions. Science 144: 313-314, 1964.

4. Butter, C. M., M. Mishkin and H. E. Rosvold. Conditioning and extinction of a food-rewarded response after selective ablations of frontal cortex in rhesus monkeys. Exp. Neurol. 7: 65-75, 1963 .

5. Butter, C. M., M. Mishkin and H. E. Rosvold. Stimulus generalization in monkeys with inferotemporal and lateral occipital lesions. In: Stimulus Generalization, edited by D. Mostofsky. Palo Alto, California: Stanford University Press, 1965.
6. Mason, W. A., P. C. Green and C. J. Posepanko. Sex differences in affective-social responses of rhesus monkeys. Behaviour. 16: 74-83, 1960.

7. Mishkin, M. Perseveration of central sets after frontal lesions in monkeys. In: Frontal Granular Cortex and Behavior, edited by J. M. Warren and K. Akert. New York: McGrawHill, 1964, Chapt. 11.

8. Pribram, K. H. and L. A. Weiskrantz. A comparison of the effects of medial and lateral cerebral resections on conditioned avoidance behavior of monkeys. J. comp. physiol. Psychol. 50: 74-80, 1957.

9. Rosvold, H. E., A. F. Mirsky and K. H. Pribram. Influence of amygdalectomy on social behavior in monkeys. J. comp. physiol. Psychol. 47: 173-178, 1954.

10. Waterhouse, I. K. Effects of prefrontal lobotomy on conditioned fear and food responses in monkeys. J. comp. physiol. Psychol. 50: 81-88, 1957. 